\title{
Optimization of the double isotope dilution
}

6 The double isotope dilution is a powerful methodology to measure accurately the ratio 7 between two isotopes of two different elements (e.g. ${ }^{238} \mathrm{Pu} /{ }^{238} \mathrm{U},{ }^{148} \mathrm{Nd} /{ }^{238} \mathrm{U}$ or $8{ }^{230} \mathrm{Th} /{ }^{238} \mathrm{U}$ ratios). To obtain the lowest possible uncertainty, some parameters must be 9 optimized: the elaboration of the spike and the proportion of the spike in the sample 10 spike mixture. A piece of code is also provided to easily calculate the optimal

11 parameters. As an example, the application of the code to ${ }^{238} \mathrm{Pu} /{ }^{238} \mathrm{U}$ and ${ }^{148} \mathrm{Nd} /{ }^{238} \mathrm{U}$

12 ratios determination in irradiated sample will be discussed.

13

14 Mass spectrometry; double isotope dilution, isotope dilution 
17 Determining the ratio between two isotopes of two elements $\left(\right.$ e.g. ${ }^{238} \mathrm{Pu} /{ }^{238} \mathrm{U},{ }^{148} \mathrm{Nd} /{ }^{238} \mathrm{U}$ 18 or ${ }^{230} \mathrm{Th} /{ }^{238} \mathrm{U}$ ratios) is of prime interest in the nuclear and the geochemistry fields. One of the main application in the nuclear field is the burnup monitoring of irradiated samples using the ${ }^{148} \mathrm{Nd} /{ }^{238} \mathrm{U}$ ratio [1-3]. The ${ }^{148} \mathrm{Nd}$ isotope have the suitable properties for burnup level examination: it is a stable fission product and requires no decay correction, it is not volatile and has no volatile precursors, it is formed exclusively by fission as it has a low neutron capture cross section and is not present in non-irradiated samples. Other applications can be the transmutation yield determination for analytical irradiation examination or to determine the capture integral cross section of different isotopes [4-6]. In geochemistry, isotopes ratios like ${ }^{230} \mathrm{Th} /{ }^{238} \mathrm{U}$ or ${ }^{226} \mathrm{Ra} /{ }^{238} \mathrm{U}$ help identifying and characterize the contamination sources [7-9]. It can also be useful to date geological objects [10-13]. These applications require measuring these ratios with the best possible accuracy (i.e. measurement trueness and precision).

Isotope dilution (ID) is the main methodology used in mass spectrometry to determine accurately the mass fraction determination of an analyte in a sample, as it is a reference calibration method [14-17]. The ID principle is to mix a known amount of a sample, with a known isotope composition, with a spike solution containing the same analyte as the sample but with a different isotope composition. This solution is called the (sample-spike) mixture and its isotope ratio reflects the sample analyte mass fraction. To obtain the best performance (i.e. the minimum mass fraction uncertainty), the mixture between the sample and the spike must be prepared carefully. The ID-TIMS require an optimal mixture isotope ratio which can be determined theoretically [15]. The mixture is then prepared to obtain a mixture isotope ratio as close as possible to the theoretical one. The ratio between two isotopes of two elements is then calculated using the mass fraction of the two elements determined with the ID methodology, the isotope abundances and the molar masses. This method requires several gravimetric preparations which can increase the uncertainties. Moreover, it can be tedious when working in glove boxes or in hot cell laboratories.

Another existing method is the double isotope dilution (DID) method: it is used to 46 directly determine the ratio between two isotopes of two elements present in a sample, 
with one of them used as a reference [6]. Similarly to the ID, the DID is based on the addition of a spike to the sample. The spike solution must contain the same two analytes as the sample with a different isotope composition. The spike can be homemade and prepared from two Certified Reference Material (CRM) or a well-recognized CRM provided by an official supplier (NIST, JRC-Geel or CETAMA for example) can be used. The mixture isotope ratios are then measured using an accurate technique such as Thermal Ionization Mass Spectrometry (TIMS) or Multi-Collector Inductively Coupled Plasma Mass Spectrometry (MC-ICP-MS). The mixture isotope ratios measurements helped to calculate the ratio between two isotopes of two elements in the sample. The benefit of the DID compared to the ID is that it is only based on the isotope ratio determination. Separation yields and weights uncertainties are not to be considered. The mixture or sample dilutions can be perform volumetrically without uncertainty degradation. Thus, implementing the DID is easier compared to the ID, especially when the experiments are performed in glove boxes or in hot-cells. To obtain the best performances for DID, some parameters like the spike solution preparation or the (sample - spike) mixture must be optimized.

Note that the DID must not be mistaken for reverse (or two-step) ID that is used when the spike is not certified. The spike material is calibrated against a well-characterized assay material with natural isotope abundance [18]. The DID must not be mistaken for the double spike technique. The double spike technique is a powerful method for correcting the instrumental mass fractionation in mass spectrometry. It is the most reliable method to obtain accurate isotope ratios of a single element [19].

This study aims at discussing and finding the optimal parameters for the DID. First, the DID will be summarized. Then, the theoretical calculations performed to find the optimal parameters will be discussed. Finally, different examples, coming from samples analyzed in the laboratory, will be evaluated. To make it as easy as possible for experimenters using the DID, a script written with open source software Octave is provided to easily determine the optimal parameters.

\section{Materials and methods}

\subsection{Overview of the double isotope dilution methodology}


78 A schematic of the DID is presented in Fig. 1. The goal of the DID is to measure the ratio between two isotopes of two elements. Element 1 (noted E) is the reference element. Isotopes of element $\mathrm{E}$ are ${ }^{\mathrm{A}} \mathrm{E}$ and ${ }^{\mathrm{B}} \mathrm{E}$. The reference isotope of $\mathrm{E}$ for the sample is the ${ }^{\mathrm{B}} \mathrm{E}$ isotope (e.g. $\left.{ }^{238} \mathrm{U}\right)$. The major isotope of the $\mathrm{CRM}$ used in the spike for element $\mathrm{E}$ is ${ }^{\mathrm{A}} \mathrm{E}$ (e.g. ${ }^{233} \mathrm{U}$ or ${ }^{235} \mathrm{U}$ ). The second element (noted element $\mathrm{Z}$ ) can be any element of the periodic table with at least 2 isotopes. The isotopes of interest for element $\mathrm{Z}$ are ${ }^{\mathrm{X}} \mathrm{Z}$ and ${ }^{\mathrm{Y}} \mathrm{Z}$. ${ }^{\mathrm{X}} \mathrm{Z}$ is the major isotope of the $\mathrm{CRM}\left(\right.$ e.g. ${ }^{242} \mathrm{Pu}$ or $\left.{ }^{150} \mathrm{Nd}\right) .{ }^{\mathrm{Y}} \mathrm{Z}$ is the isotope of interest for the sample (e.g. ${ }^{238} \mathrm{Pu}$ or ${ }^{148} \mathrm{Nd}$ ). The "spike" term refers to the solution containing $\mathrm{E}$ and $\mathrm{Z}$ elements with a known ${ }^{\mathrm{Y}} \mathrm{Z} / \mathrm{A} E$ ratio. The spike can be obtained from a CRM containing both elements or manufactured using two CRMs. For better clarity and concision, the following nomenclature was used in the manuscript:

- $\quad T$ refers to the spike (or tracer). It contains both elements $\mathrm{E}$ and $\mathrm{Z}$

- $\quad M$ refers to the (sample - spike) mixture

- $\quad S$ refers to the sample

- $\quad C R M_{E}$ refer to the CRM containing only element $\mathrm{E}$

- $\quad C R M_{Z}$ refer to the CRM containing only element $\mathrm{Z}$

- $\quad n$ is the amount in mol

- $\quad C$ is the amount concentration in $\mathrm{mol} \mathrm{g}^{-1}$

- $\quad(\% A)$ refers to the ${ }^{\mathrm{A}} \mathrm{E}$ isotope abundance of element $\mathrm{E}$ (A being the major isotope

- $(\% B)$ refers to the ${ }^{\mathrm{B}} \mathrm{E}$ isotope abundance of element $\mathrm{E}$ (B being the reference of the CRM or spike)

100 isotope of the sample) of the CRM or spike) 
$102-(\% Y)$ refers to the ${ }^{\mathrm{Y}} \mathrm{Z}$ isotope abundance of element $\mathrm{Z}$ (Y being the reference

103 isotope of the sample)

$104-u$ is the uncertainty with a coverage factor at $\mathrm{k}=1$

$105-u_{r}$ is the relative uncertainty with a coverage factor at $\mathrm{k}=1$

$106-\quad \kappa$ is the proportion of element $\mathrm{E}$ in the spike solution $(\mathrm{T})$

$107-(1-\kappa)$ is the proportion of element $\mathrm{Z}$ in the spike solution $(\mathrm{T})$

$108-\lambda$ is the proportion of the spike solution $(\mathrm{T})$ in the mixture (M)

109 2.1.2. Double isotope dilution formula

110 The $\left({ }^{\mathrm{B}} \mathrm{E} /{ }^{\mathrm{A}} \mathrm{E}\right)_{\mathrm{M}}$ ratio can be calculated from the E element sample and spike amount and 111 the E element isotope abundances (Eq. (1), Fig. 1).

$$
\begin{gathered}
\left(\frac{{ }^{B} E}{{ }^{A} E}\right)_{M}=\frac{n(E)_{S} \cdot(\% B)_{S}+n(E)_{T} \cdot(\% B)_{T}}{n(E)_{S} \cdot(\% A)_{S}+n(E)_{T} \cdot(\% A)_{T}} \\
(\% A)_{S}=(\% B)_{S} \cdot\left(\frac{{ }^{A} E}{{ }^{B} E}\right)_{S} \\
(\% B)_{T}=(\% A)_{T} \cdot\left(\frac{{ }^{B} E}{{ }^{A} E}\right)_{T}
\end{gathered}
$$

112 Combining Eq. (1), (2) and (3) leads to Eq. (4).

$$
\left(\frac{{ }^{B} E}{{ }^{A} E}\right)_{M}=\frac{n(E)_{S} \cdot(\% B)_{S}+n(E)_{T} \cdot\left(\frac{{ }^{B} E}{{ }^{A} E}\right)_{T} \cdot(\% A)_{T}}{n(E)_{S} \cdot(\% B)_{S} \cdot\left(\frac{{ }^{A} E}{{ }^{B} E}\right)_{S}+n(E)_{T} \cdot(\% A)_{T}}
$$

113 Rearranging Eq. (4) leads to Eq. (5).

$$
n(E)_{S} \cdot(\% B)_{S}=n(E)_{T} \cdot(\% A)_{T} \cdot \frac{\left(\left(\frac{{ }^{B} E}{{ }^{A} E}\right)_{M}-\left(\frac{{ }^{B} E}{{ }^{A} E}\right)_{T}\right)}{\left(1-\left(\frac{{ }^{B} E}{{ }^{A} E}\right)_{M} \cdot\left(\frac{{ }^{A} E}{{ }^{B} E}\right)_{S}\right)}
$$

114 The same equation as Eq. (5) can be obtained for element Z (Eq. (6)). 


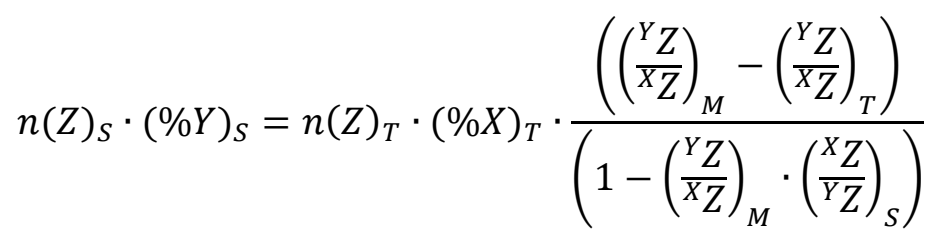

115 Dividing Eq. (6) by Eq. (5) leads to the $\left({ }^{\mathrm{Y} Z} /{ }^{\mathrm{B}} \mathrm{E}\right) \mathrm{s}$ ratio and the DID formula (Eq. (7)).

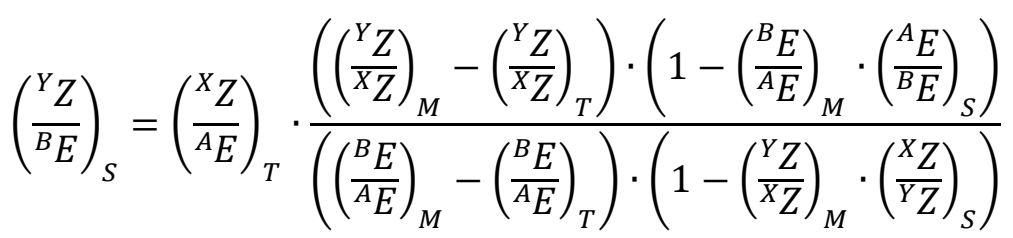

\section{2.1.3. Uncertainty estimation}

117 The $\left({ }^{\mathrm{Y} Z} /{ }^{\mathrm{B}} \mathrm{E}\right)_{\mathrm{S}}$ ratio uncertainty $\left(u\left[\left({ }^{Y} \mathrm{Z} /{ }^{B} E\right)_{S}\right], \mathrm{k}=1\right.$, Eq. (8)) was estimated by combining

118 the uncertainties from each term of the DID equation (Eq. (7)) [20]. The terms of Eq. (7)

119 were considered as not correlated, so no covariance terms are needed. 


$$
\begin{aligned}
& u^{2}\left(\left(\frac{{ }^{Y} Z}{{ }^{B} E}\right)_{S}\right)=\left(\frac{\left(\left(\frac{{ }^{Y} Z}{{ }^{X} Z}\right)_{M}-\left(\frac{{ }^{Y} Z}{{ }^{X} Z}\right)_{T}\right) \cdot\left(\left(\frac{{ }^{B} E}{{ }^{A} E}\right)_{M} \cdot\left(\frac{{ }^{A} E}{{ }^{B} E}\right)_{S}-1\right)}{\left(\left(\frac{{ }^{B} E}{{ }^{A} E}\right)_{M}-\left(\frac{{ }^{B} E}{{ }^{A} E}\right)_{T}\right) \cdot\left(\left(\frac{{ }^{Y} Z}{{ }^{X} Z}\right)_{M} \cdot\left(\frac{{ }^{X} Z}{{ }^{Y} Z}\right)_{S}-1\right)}\right)^{2} \cdot u^{2}\left(\left(\frac{{ }^{X} Z}{{ }^{A} E}\right)_{T}\right) \\
& +\left(-\left(\frac{{ }^{X} Z}{{ }^{A} E}\right)_{T} \cdot \frac{\left(\left(\frac{{ }^{B} E}{{ }^{A} E}\right)_{M} \cdot\left(\frac{{ }^{A} E}{{ }^{B} E}\right)_{S}-1\right)}{\left(\left(\frac{{ }^{B} E}{{ }^{A} E}\right)_{M}-\left(\frac{{ }^{B} E}{{ }^{A} E}\right)_{T}\right) \cdot\left(\left(\frac{{ }^{Y} Z}{{ }^{X}}\right)_{M} \cdot\left(\frac{{ }^{X} Z}{{ }^{Z} Z}\right)_{S}-1\right)}\right)^{2} \cdot u^{2}\left(\left(\frac{{ }^{Y} Z}{{ }^{X} Z}\right)_{T}\right) \\
& +\left(\left(\frac{{ }^{X} Z}{{ }^{A} E}\right)_{T} \cdot \frac{\left(\left(\frac{{ }^{Y} Z}{{ }^{X} Z}\right)_{M}-\left(\frac{{ }^{Y} Z}{{ }^{X} Z}\right)_{T}\right) \cdot\left(\left(\frac{{ }^{B} E}{{ }^{A} E}\right)_{M} \cdot\left(\frac{{ }^{A} E}{{ }^{B} E}\right)_{S}-1\right)}{\left(\left(\frac{{ }^{B} E}{{ }^{A} E}\right)_{M}-\left(\frac{{ }^{B} E}{{ }^{A} E}\right)_{T}\right)^{2} \cdot\left(\left(\frac{{ }^{Y} Z}{{ }^{X} Z}\right)_{M} \cdot\left(\frac{{ }^{X} Z}{{ }^{X} Z}\right)_{S}-1\right)}\right)^{2} \cdot u^{2}\left(\left(\frac{{ }^{B} E}{{ }^{A} E}\right)_{T}\right) \\
& +\left(-\left(\frac{{ }^{X} Z}{{ }^{A} E}\right)_{T} \cdot\left(\frac{{ }^{Y} Z}{{ }^{X} Z}\right)_{M} \cdot \frac{\left(\left(\frac{{ }^{Y} Z}{{ }^{X} Z}\right)_{M}-\left(\frac{{ }^{Y} Z}{{ }^{X} Z}\right)_{T}\right) \cdot\left(\left(\frac{{ }^{B} E}{{ }^{A} E}\right)_{M} \cdot\left(\frac{{ }^{B} E}{{ }^{B} E}\right)_{S}-1\right)}{\left(\left(\frac{{ }^{B} E}{{ }^{A} E}\right)_{M}-\left(\frac{{ }^{B} E}{{ }^{A} E}\right)_{T}\right)^{2} \cdot\left(\left(\frac{{ }^{Y} Z}{{ }^{X} Z}\right)_{M} \cdot\left(\frac{{ }^{X} Z}{{ }^{X} Z}\right)_{S}-1\right)}\right)^{2} \\
& \cdot u^{2}\left(\left(\frac{{ }^{X} Z}{{ }^{Y} Z}\right)_{S}\right) \\
& +\left(\left(\frac{{ }^{X} Z}{{ }^{A} E}\right)_{T} \cdot\left(\frac{{ }^{B} E}{{ }^{A} E}\right)_{M} \cdot \frac{\left(\left(\frac{{ }^{Y} Z}{{ }^{X} Z}\right)_{M}-\left({ }^{{ }^{Y}}{ }^{{ }^{X} Z}\right)_{T}\right)}{\left(\left(\frac{{ }^{B} E}{{ }^{A} E}\right)_{M}-\left(\frac{{ }^{B} E}{{ }^{A} E}\right)_{T}\right) \cdot\left(\left(\frac{{ }^{Y} Z}{{ }^{X} Z}\right)_{M} \cdot\left(\frac{{ }^{X} Z}{{ }^{Y} Z}\right)_{S}-1\right)}\right)^{2}
\end{aligned}
$$

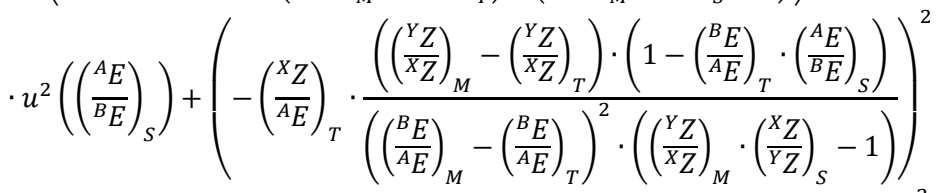

$$
\begin{aligned}
& \cdot u^{2}\left(\left(\frac{{ }^{B} E}{{ }^{A} E}\right)_{M}\right)+\left(\left(\frac{{ }^{X} Z}{{ }^{A} E}\right)_{T} \cdot \frac{\left(\left(\frac{{ }^{Y} Z}{{ }^{X} Z}\right)_{T} \cdot\left(\frac{{ }^{X} Z}{{ }^{Y} Z}\right)_{S}-1\right) \cdot\left(\left(\frac{{ }^{B} E}{{ }^{A} E}\right)_{M} \cdot\left(\frac{{ }^{B} E}{{ }^{B} E}\right)_{S}-1\right)}{\left(\left(\frac{{ }^{B} E}{{ }^{A} E}\right)_{M}-\left(\frac{{ }^{B} E}{{ }^{A} E}\right)_{T}\right) \cdot\left(\left(\frac{{ }^{Y} Z}{{ }^{X} Z}\right)_{M} \cdot\left(\frac{{ }^{X} Z}{{ }^{Y} Z}\right)_{S}-1\right)^{2}}\right)^{2} \\
& \cdot u^{2}\left(\left(\frac{{ }^{Y} Z}{{ }^{X} Z}\right)_{M}\right)
\end{aligned}
$$

\subsection{Optimization of the double isotope dilution methodology}

121 The DID methodology requires a parameters optimization to obtain the most accurate

122 results: i.e. the minimal $\left({ }^{\mathrm{Y}} \mathrm{Z} /{ }^{\mathrm{B}} \mathrm{E}\right) \mathrm{s}$ relative uncertainty. Two different optimizations can

123 be performed. The first optimization is needed if the spike solution ( $T$ ) must be prepared 124 using 2 CRMs. In this case, it is possible to optimize the proportion of each element in 125 the spike solution $(\mathrm{T})(\kappa$ parameter for element $\mathrm{E}$ and $(1-\kappa)$ for element $\mathrm{Z}$ ) and the 126 proportion of the spike solution $(\mathrm{T})$ in the mixture $(\mathrm{M})(\lambda$ parameter). The second one is if the spike solution (T) containing both elements is already prepared or using a CRM solution commercially available. In this case the only parameter which can be optimized is the proportion of the spike solution $(\mathrm{T})$ in the mixture ( $\lambda$ parameter). 
130

131

132 The $\left({ }^{\mathrm{X}} \mathrm{Z} /{ }^{\mathrm{A}} \mathrm{E}\right)_{\mathrm{T}}$ ratio can be calculated as a function of the proportion of $\mathrm{E}$ and $\mathrm{Z}$ CRM in 133 the spike ( $\kappa$ and (1- $\kappa)$ parameters), amount concentrations and isotope abundances 134 (Eq. (9)). Please note $(\% A),(\% B),(\% X)$ and $(\% Y)$ are the same in the CRM and in the 135 136

$$
\left(\frac{{ }^{X} Z}{{ }^{A} E}\right)_{T}=\frac{(1-\kappa) \cdot C(Z)_{C R M_{Z}} \cdot(\% X)_{T}}{\kappa \cdot C(E)_{C R M_{E}} \cdot(\% A)_{T}}
$$

137 The $\left({ }^{\mathrm{B}} \mathrm{E} / \mathrm{A} E\right)_{M}$ ratio can be calculated as a function the proportion of $\mathrm{E} C \mathrm{CRM}$ in the spike 138 ( $\kappa$ parameter), the proportion of spike in the mixture ( $\lambda$ parameter), amount 139 concentrations and isotope abundances (Eq. (10)).

$$
\left(\frac{{ }^{B} E}{{ }^{A} E}\right)_{M}=\frac{\lambda \cdot \kappa \cdot C(E)_{C R M_{E}} \cdot(\% B)_{T}+(1-\lambda) \cdot C(E)_{S} \cdot(\% B)_{S}}{\lambda \cdot \kappa \cdot C(E)_{C R M_{E}} \cdot(\% A)_{T}+(1-\lambda) \cdot n(E)_{S} \cdot(\% A)_{S}}
$$

140 The $\left({ }^{\mathrm{Y} Z} /{ }^{\mathrm{X}} \mathrm{Z}\right)_{\mathrm{M}}$ ratio can be calculated by the same way using Eq. (11).

$$
\left(\frac{{ }^{Y} Z}{{ }^{X} Z}\right)_{M}=\frac{\lambda \cdot(1-\kappa) \cdot C(Z)_{C R M_{Z}} \cdot(\% Y)_{T}+(1-\lambda) \cdot C(Z)_{S} \cdot(\% Y)_{S}}{\lambda \cdot(1-\kappa) \cdot C(Z)_{C R M_{Z}} \cdot(\% X)_{T}+(1-\lambda) \cdot C(Z)_{S} \cdot(\% X)_{S}}
$$

141 By introducing Eqs. (9), (10) and (11) in Eqs. (7) and (8), the $\left({ }^{\mathrm{Y} Z} /{ }^{\mathrm{B}} \mathrm{E}\right) \mathrm{s}$ ratio relative 142 uncertainty $\left(u_{r}\left[\left({ }^{\mathrm{Y} Z} /{ }^{\mathrm{B}} \mathrm{E}\right) \mathrm{S}\right]\right)$ can be expressed as a function of $\lambda$ and $\kappa$ (Eq. (12)).

$$
u_{r}\left(\left(\frac{{ }^{Y} Z}{{ }^{B} E}\right)_{S}\right)=f(\lambda, \kappa)
$$

143 Finding the $\lambda$ and $\kappa$ optimal parameters is simply a matter of locating the minimal 144 relative uncertainty of the $\left({ }^{\mathrm{Y} Z} /{ }^{\mathrm{B}} \mathrm{E}\right)_{\mathrm{S}}$ ratio. It helps obtaining the most accurate result. 145 The $\left({ }^{\mathrm{B}} \mathrm{E} /{ }^{\mathrm{A}} \mathrm{E}\right)_{\mathrm{M}}$ and $\left({ }^{\mathrm{Y}} \mathrm{Z} / \mathrm{X}^{\mathrm{X}}\right)_{\mathrm{M}}$ optimal mixture isotope ratios are then calculated by 146 introducing optimal $\lambda$ and $\kappa$ parameters in Eqs. (10) and (11).

147 It is possible to plot the function described in Eq. (12) to study the variation of the 148 relative uncertainty as a function of $\lambda$ and $\kappa$. An example of this plot, hereafter referred 149 to as a contour plot, is showed in Fig. 2. The contours are spaced out with intervals of 
$1501 \%$ of the optimal relative uncertainty. The plot is cut off so that only contours within

$15120 \%$ of the minimal error are shown. The contour plot is useful to show how robust the

152 optimal parameters are. In fact, the sample amount concentration $\left(c(E)_{S}\right)$ and $\left.\mathrm{c}(Z)_{S}\right)$ are

153 generally not accurately known. It can be provided by different sources: neutronic

154 simulation code, fast analytical technic like UV/Vis spectrometry or L-line X-ray

155 fluorescence or estimated using the results from previous experiments. It is difficult to

156 mix the sample and the spike with the exact and optimal proportions. So, it is important

157 to understand how the error of the relative uncertainty varies around the $\lambda$ and $\kappa$ optimal

158 parameters.

159

160

161 If the homemade spike is already prepared or if using a commercially available spike,

164

$$
\left(\frac{{ }^{B} E}{{ }^{A} E}\right)_{M}=\frac{\lambda \cdot C(E)_{T} \cdot(\% B)_{T}+(1-\lambda) \cdot C(E)_{S} \cdot(\% B)_{S}}{\lambda \cdot C(E)_{T} \cdot(\% A)_{T}+(1-\lambda) \cdot C(E)_{S} \cdot(\% A)_{S}}
$$

In the same way, the $\left({ }^{\mathrm{Y}} \mathrm{Z} /{ }^{\mathrm{X}} \mathrm{Z}\right)_{\mathrm{M}}$ ratio can be calculated (Eq. (14)).

$$
\left(\frac{{ }^{Y} Z}{{ }^{X} Z}\right)_{M}=\frac{\lambda \cdot C(Z)_{T} \cdot(\% Y)_{T}+(1-\lambda) \cdot C(Z)_{S} \cdot(Y)_{S}}{\lambda \cdot C(Z)_{T} \cdot(\% X)_{T}+(1-\lambda) \cdot n(Z)_{S} \cdot(\% X)_{S}}
$$

169 By introducing Eq. (13) and (14) in Eq. (7) and (8), the $\left({ }^{\mathrm{Y} Z} /{ }^{\mathrm{B}} \mathrm{E}\right) \mathrm{s}$ ratio relative 170 uncertainty as a function of $\lambda$ is calculated (Eq. (15)).

$$
u_{r}\left(\left(\frac{{ }^{Y} Z}{{ }^{B} E}\right)_{S}\right)=f(\lambda)
$$


171 Finding the $\lambda$ optimal value is simply a matter of locating the minimal relative

172 uncertainty of the sample ${ }^{\mathrm{Y}} \mathrm{Z} /{ }^{\mathrm{B}} \mathrm{E}$ ratio. The $\left({ }^{\mathrm{B}} \mathrm{E} /{ }^{\mathrm{A}} \mathrm{E}\right)_{\mathrm{M}}$ and $\left({ }^{\mathrm{Y} Z} /{ }^{\mathrm{X}} \mathrm{Z}\right)_{\mathrm{M}}$ optimal ratio are 173 then calculated by introducing the optimal $\lambda$ in Eq. (13) and (14). To understand how 174 the error varies around the $\lambda$ optimal value, the error of the relative uncertainty as a 175 function of $\lambda$ can be drawn.

177 All the calculation were implemented in a script written with the open source software

178

Octave [21], version 5.1.0. To start the script, unzip the "double_ID_optimization.zip" file available in the supplementary materials. Start Octave software and set the browser directory to the appropriate folder where the unzipped folder is located. Starting the script is performed by typing "startup_DID" in the Octave command window. Then, the script allows to select which parameters need to optimized: simultaneous optimization of $\lambda$ and $\kappa$ parameters or optimization of the $\lambda$ parameter. Then, all parameters, including the choice of elements and isotopes, must be selected. The default parameters can be modified in the "privateldefault_value_data_double_ID.m" file. Once the calculation is complete, the optimal parameters, including the optimal mixture isotope ratios, are displayed in the Octave command windows. The plot are also displayed. The plot can be saved as a $8 \mathrm{~cm} \times 8 \mathrm{~cm}$ ".png” file. The results and the raw data can be saved in a ".txt" file.

\subsection{Experimental}

As concrete examples, experiments performed on samples from the DIAMINO irradiation were considered in details [4, 22]. The DIAMINO irradiation was an analytical irradiation experiment performed on $\mathrm{UAmO}_{2}$ discs to study their behaviors under irradiation, to determine the americium transmutation yield and to study the influence of the microstructure on the gas release as a function of temperature. Among the determinations, ${ }^{238} \mathrm{Pu} /{ }^{238} \mathrm{U},{ }^{241} \mathrm{Am} /{ }^{238} \mathrm{U}$ and ${ }^{148} \mathrm{Nd} /{ }^{238} \mathrm{U}$ ratios were of prime interest. In these examples, ${ }^{238} \mathrm{Pu} /{ }^{238} \mathrm{U}$ and ${ }^{148} \mathrm{Nd} /{ }^{238} \mathrm{U}$ ratios were investigated in more details.
Thus, element $\mathrm{Z}$ can be $\mathrm{Pu}$ and $\mathrm{Nd}$ alternatively. The first element $\mathrm{E}$ was chosen as 
uranium as it is usually used as reference in the nuclear field. Its reference isotope is $200 \quad{ }^{\mathrm{B}} \mathrm{E}={ }^{238} \mathrm{U}$.

201 All theoretical investigations were performed on the same sample (DIAMINO sample $[4,22])$. The characteristics of the sample have been summarized in Table 1 . The isotope ratios, abundances and uncertainties of the sample were determined in previous studies $[4,22]$. The $\mathrm{U}$ and $\mathrm{Pu}$ amount concentration of the sample were estimated using a L-line X-ray fluorescence analysis located in a shielded line [23]. It is a nondestructive, non-invasive and relatively fast technique giving the actinide amount concentration with an uncertainty of about $10 \%$. This measurement is important to obtain a reliable estimation of the $\mathrm{U}$ and $\mathrm{Pu}$ amount concentration in the sample before implementing the DID. The Nd amount concentration was estimated using a neutronic simulation code as $\mathrm{Nd}$ cannot be measure using L-line $\mathrm{X}$-ray fluorescence analysis.

211 The mixture isotope ratios relative uncertainties $\left(u_{r}\left[\left({ }^{B} E / A E\right)_{M}\right]\right.$ and $\left.u_{r}\left[\left({ }^{Y} Z /{ }^{X} Z\right)_{M}\right]\right)$ were 212 set at $0.07 \%(\mathrm{k}=1)$, corresponding to the International Target Value (ITV) for a $213{ }^{238} \mathrm{U} /{ }^{235} \mathrm{U}$ isotope ratio of about 1 [24].

\section{Results and discussion}

\subsection{Simultaneous optimization of $\lambda$ and $\kappa$ parameters}

216 For such case, $\kappa$ is plotted versus $\lambda$, and a contour plot is presented with each line 217 representing a $1 \%$ variation of the minimal relative uncertainty.

\subsection{1. ${ }^{238} \mathrm{Pu} /{ }^{238} \mathrm{U}$ ratio determination}

In the first case, the spike is manufactured from two uranium and plutonium CRM. The

220 reference uranium and plutonium isotope of the sample is ${ }^{238} \mathrm{U}$ (i.e. ${ }^{\mathrm{B}} \mathrm{E}={ }^{238} \mathrm{U}$ ) and ${ }^{238} \mathrm{Pu}$

221 (i.e. ${ }^{\mathrm{Y}} \mathrm{Z}={ }^{238} \mathrm{Pu}$ ), respectively. The natural choice to prepare the uranium spike is a CRM 222 enriched with ${ }^{233} \mathrm{U}$ or ${ }^{235} \mathrm{U}$ isotope (i.e. ${ }^{\mathrm{A}} \mathrm{E}={ }^{235} \mathrm{U}$ or ${ }^{233} \mathrm{U}$ ). For plutonium, a CRM 223 enriched with ${ }^{242} \mathrm{Pu}$ isotope is a good choice to prepare the spike (i.e. ${ }^{\mathrm{X}} \mathrm{Z}={ }^{242} \mathrm{Pu}$ ). 
225 In this first example, the U CRM, enriched in ${ }^{235} \mathrm{U}$ (i.e. ${ }^{\mathrm{A}} \mathrm{E}={ }^{235} \mathrm{U}$ ), was the IRMM 054

226 CRM provided by the Joint Research Centre of the European Commission (EC-JRC).

227 This U CRM was diluted gravimetrically to obtain a uranium mass fraction near $22810 \mu \mathrm{g} \mathrm{g}^{-1}$. The $\mathrm{Pu} \mathrm{CRM}$, enriched in ${ }^{242} \mathrm{Pu}$ isotope (i.e. ${ }^{\mathrm{X}} \mathrm{Z}={ }^{242} \mathrm{Pu}$ ), was the IRMM 229 049d CRM provided by EC-JRC. This Pu material was diluted gravimetrically to obtain 230 a plutonium mass fraction near $5 \mu \mathrm{g} \mathrm{g}^{-1}$. The characteristics of the CRM, with the 231 appropriate notation, are summarized by example 1 in Table 1 . The optimal $\lambda$ and $\kappa$ 232 parameters were 0.84 and 0.30 , respectively. This corresponds to $\left({ }^{\mathrm{B}} \mathrm{E} /{ }^{\mathrm{A}} \mathrm{E}\right)_{\mathrm{M}}$ and $\left.233\left({ }^{\mathrm{Y}} /{ }^{\mathrm{X}} \mathrm{Z}\right)_{\mathrm{M}}\right)$ ratios measured at 3.49 and 0.0769 , respectively. The contour plot is 234 represented in Fig. 2. In this example, the optimal parameters are quite robust as the 235 relative uncertainty surface is flat: there are a wide range of $\lambda$ and $\kappa$ values that are 236 within $1 \%$ of the minimal relative uncertainty. It is easy to manufacture the spike and 237 the mixture without the risk to lose the measurement accuracy. The minimal relative 238 uncertainty was estimated to $0.17 \%(\mathrm{k}=1)$. This uncertainty corresponds to the 239 uncertainty linked to the DID uncertainty (Eq. (8)) and does not take into account the 240 repeatability.

\subsubsection{Solutions enriched with ${ }^{233} U$ and ${ }^{242} P u$ isotopes}

242 As second example the uranium CRM used was a CRM enriched in ${ }^{233} \mathrm{U}$ isotope (i.e. $\left.243{ }^{\mathrm{A}} \mathrm{E}={ }^{233} \mathrm{U}\right)$ : the IRMM-051 CRM. The CRM characteristics for example 2 are 244 summarized in Table 1. All the other parameters are the same as in example 1 (Pu CRM 245 and sample characteristics). Using a uranium CRM enriched in ${ }^{233} \mathrm{U}$ isotope is 246 interesting as the sample generally contains no ${ }^{233} \mathrm{U}$ isotope: $(\% A)_{s}=0$ and $u\left(A B_{S}\right)=0$. 247 The optimal $\lambda$ and $\kappa$ parameters were calculated using the data in example 2 in Table 1. 248 However, in such case, the simultaneous optimization of $\lambda$ and $\kappa$ cannot work for mathematical reasons. Indeed, the $\kappa$ parameter approaches 0 , which makes no sense: it 250 is impossible to compute the $\left({ }^{\mathrm{Y} Z} /{ }^{\mathrm{B}} \mathrm{E}\right)_{\mathrm{S}}$ ratio with a spike containing no $\mathrm{U}$ element. 251 However, the plot in Fig. 3, helps finding the optimal $\lambda$ and $\kappa$ parameters. The surface 252 where the relative uncertainty is within $1 \%$ of the minimal relative uncertainty is 253 relatively flat: in this central surface, the relative uncertainty is between $0.1380 \%$ and $2540.1394 \%(\mathrm{k}=1)$. Graphically, it exists a lot of $\lambda$ and $\kappa$ parameters pairs for the best 255 conditions: one pair, presented in Fig. 3, could be $\lambda=0.8$ and $\kappa=0.2$. Thus, when the 
256 major isotope of a spike is not present in the sample, the $\lambda$ and $\kappa$ optimal parameters 257 can be determined graphically.

\subsection{2. ${ }^{148} \mathrm{Nd} /{ }^{238} \mathrm{U}$ ratio determination}

259 In this example, the optimal parameters for the determination of the ${ }^{148} \mathrm{Nd} /{ }^{238} \mathrm{U}$ ratio 260 were studied (example 3 in Table 1). The laboratory has already prepared a homemade 261 characterized $\mathrm{Nd}$ material [4]: this $\mathrm{Nd}$ material solution was prepared by dissolving a $262{ }^{150} \mathrm{Nd}$ enriched (95\%) non-radioactive neodymium oxide powder in $3 \mathrm{~mol} \mathrm{~L}^{-1} \mathrm{HNO}_{3}$.

263 The $\mathrm{Nd}$ mass fraction of the $\mathrm{Nd}$ material is about $7.5 \mu \mathrm{g} \mathrm{g}^{-1}\left(\mathrm{c}\left(Z_{T}\right)=0.0499 \times 10^{-6}\right.$ $\left.264 \mathrm{~mol} \mathrm{~g}^{-1}\right)$. The $\mathrm{U}$ CRM, enriched in ${ }^{235} \mathrm{U}$ isotope, is the IRMM $054 \mathrm{CRM}$. The 265 characteristics of the material and the sample are summarized in example 3 in Table 1.

266 The optimal $\lambda$ and $\kappa$ parameters were 0.59 and 0.994 , respectively. The optimal 267 parameters indicates that the spike must contain mostly $\mathrm{U}$ (only $0.06 \%$ of $\mathrm{Nd}$ material 268 in the spike). The contour plot is represented in Fig. 4.a. In this example, the optimal 269 values is not robust as the relative uncertainty surface is not flat. It exist a small region 270 around the $\kappa$ and $\lambda$ values to obtain the minimal uncertainty. A small error on the spike 271 preparation will have a large impact on the relative uncertainty. In this case, diluting 272 the Nd material would help obtaining more robust parameters.

273 So, the $\lambda$ and $\kappa$ parameters were optimized again using a $\mathrm{Nd}$ material diluted 100 -fold: 274 the $\mathrm{Nd}$ mass fraction is about $0.075 \mu \mathrm{g} \mathrm{g}^{-1}\left(c\left(Z_{T}\right)=0.0499 \times 10^{-8} \mathrm{~mol} \mathrm{~g}^{-1}\right)$. All of the 275 other parameters were unchanged (example 3 in Table 1). The optimal $\lambda$ and $\kappa$ 276 parameters were calculated and are 0.69 and 0.61 , respectively. The contour plot is 277 represented in Fig. 4.b. The optimum is now robust as the relative uncertainty surface 278 is flat: there are a wide range of $\lambda$ and $\kappa$ values that are within $1 \%$ of the minimal 279 relative uncertainty. It is now easier to mix the $\mathrm{U}$ and $\mathrm{Nd}$ materials to obtain the 280 appropriate spike. With these optimal parameters, the $\left({ }^{\mathrm{B}} \mathrm{E} /{ }^{\mathrm{A}} \mathrm{E}\right)_{\mathrm{M}}$ and $\left({ }^{\mathrm{Y} Z} / \mathrm{X}^{\mathrm{X}}\right)_{\mathrm{M}}$ mixture 281 ratio were 4.10 and 0.0117 , respectively. The minimal uncertainty was estimated to $2820.30 \%(\mathrm{k}=1)$.

283 3.2. Optimization of the $\lambda$ parameter 
284 In this example a spike enriched in both elements that was already prepared or using a 285 CRM is used (example 4 in Table 1). The IRMM 046c CRM, provided by EC-JRC was 286 used in this example. It is a spike solution enriched in both ${ }^{233} \mathrm{U}$ and ${ }^{242} \mathrm{Pu}$ isotopes. 287 Uranium and plutonium amount concentrations and isotope abundances of the spike are 288 certified (see Table 1): that means the $\kappa$ parameter cannot be optimize and only the $\lambda$ 289 parameter can in such case. Thus, the error for the ${ }^{238} \mathrm{Pu} /{ }^{238} \mathrm{U}$ ratio relative uncertainty 290 as a function of $\lambda$ is plotted.

291 In this example, the minimal relative uncertainty was found for $\lambda=0.14$. The minimal 292 uncertainty was estimated to $0.11 \%(\mathrm{k}=1)$. This corresponds to $\left({ }^{\mathrm{B}} \mathrm{E} /{ }^{\mathrm{A}} \mathrm{E}\right)_{\mathrm{M}}$ and $293\left({ }^{\mathrm{X}} \mathrm{Z} /{ }^{\mathrm{Y}} \mathrm{Z}\right)_{\mathrm{M}}$ ratios measured at 0.288 and 0.180 , respectively. The error for the ${ }^{238} \mathrm{Pu} /{ }^{238} \mathrm{U}$ 294 ratio relative uncertainty as a function of $\lambda$ is shown in Fig. 5.a. In this theoretical study, 295 the relative uncertainty is almost stable around the optimal $\lambda$ parameter but only for $\lambda$ 296 values higher than the $\lambda$ optimal parameter. For $\lambda$ values lower than the optimal $\lambda$ 297 parameter, the relative uncertainty increases rapidly. As the uranium and plutonium 298 amount concentration is generally not known accurately, there is a high risk to degrade 299 the accuracy measurement when performing the sample spike mixture. As the dilution 300 have no impact on the $\left({ }^{\mathrm{X}} \mathrm{Z} /{ }^{\mathrm{A}} \mathrm{E}\right)_{\mathrm{T}}$ ratio uncertainty, it will be interesting to dilute the spike 301 to obtain a more robust optimal $\lambda$ parameter.

302 The $\lambda$ parameter was optimized using the IRMM-046c CRM diluted 10-fold: $303 c\left(E_{T}\right)=4.4742 \times 10^{-7} \mathrm{~mol} \mathrm{~g}^{-1}$ and $c\left(Z_{T}\right)=0.37519 \times 10^{-7} \mathrm{~mol} \mathrm{~g}^{-1}$. All the others 304 parameters were the same as example 4 in Table 1: similarly, the ${ }^{\mathrm{Y}} \mathrm{Z} /{ }^{\mathrm{A}} \mathrm{E}$ ratio of the 305 spike remains constant whatever the dilution factor. The optimal $\lambda$ parameter is now 306 equal to 0.62 . As expected, the minimal relative uncertainty remains constant $(0.11 \%$, $307 \mathrm{k}=1$ ) as the dilution does not affect the isotope ratio. The error for the relative 308 uncertainty as a function of $\lambda$ is shown in Fig. 5.b. The $\lambda$ parameter is now more robust: 309 the relative uncertainty is stable around the optimal $\lambda$ parameter. There are a wide range 310 of $\lambda$ values corresponding to the minimal relative uncertainty.

\section{Conclusion}

312 The DID is a powerful method to determine two isotopes ratio of two elements present 313 in a sample, with one of them used as a reference. As it is only based on isotope ratio 
314 measurement, accurate measurements can be obtained. To obtain the best performance, 315 the parameters must be set carefully, especially the spike production and the (sample 316 spike) mixture. This work comes along whit a piece of code that can be found in the 317 supplementary material, to easily calculate the optimal parameters. The source code is 318 freely available and can be modified if needed by individual users. 
Table 1: Parameters used for the theoretical study to find the optimal parameters of the DID. The relative uncertainty are expressed with a coverage factor at $\mathrm{k}=1$

\begin{tabular}{|c|c|c|c|c|}
\hline Example & 1 & 2 & 3 & 4 \\
\hline Ratio of interest & ${ }^{238} \mathrm{Pu} /{ }^{238} \mathrm{U}$ & ${ }^{238} \mathrm{Pu} /{ }^{238} \mathrm{U}$ & ${ }^{148} \mathrm{Nd} /{ }^{238} \mathrm{U}$ & ${ }^{238} \mathrm{Pu} /{ }^{238} \mathrm{U}$ \\
\hline Element $1(\mathrm{E})$ & $\mathrm{U}$ & $\mathrm{U}$ & $\mathrm{U}$ & $\mathrm{U}$ \\
\hline Element $2(Z)$ & $\mathrm{Pu}$ & $\mathrm{Pu}$ & $\mathrm{Nd}$ & $\mathrm{Pu}$ \\
\hline $\begin{array}{c}{ }^{\mathrm{A}} \mathrm{E} \text { isotope } \\
\text { (spike major isotope) }\end{array}$ & ${ }^{235} \mathrm{U}$ & ${ }^{233} \mathrm{U}$ & ${ }^{235} \mathrm{U}$ & ${ }^{233} \mathrm{U}$ \\
\hline $\begin{array}{c}{ }^{\mathrm{B}} \mathrm{E} \text { isotope } \\
\text { (sample reference } \\
\text { isotope) }\end{array}$ & ${ }^{238} \mathrm{U}$ & ${ }^{238} \mathrm{U}$ & ${ }^{238} \mathrm{U}$ & ${ }^{238} \mathrm{U}$ \\
\hline $\begin{array}{c}\mathrm{x}_{\mathrm{Z}} \text { isotope } \\
\text { (spike major isotope) }\end{array}$ & ${ }^{242} \mathrm{Pu}$ & ${ }^{242} \mathrm{Pu}$ & ${ }^{150} \mathrm{Nd}$ & ${ }^{242} \mathrm{Pu}$ \\
\hline $\begin{array}{c}{ }^{\mathrm{Y} Z} \text { isotope } \\
\text { (sample reference } \\
\text { isotope) }\end{array}$ & ${ }^{238} \mathrm{Pu}$ & ${ }^{238} \mathrm{Pu}$ & ${ }^{148} \mathrm{Nd}$ & ${ }^{238} \mathrm{Pu}$ \\
\hline CRM & $\begin{array}{l}\text { U: IRMM 054 } \\
\text { Pu: IRMM 49d }\end{array}$ & $\begin{array}{l}\text { U: IRMM } 051 \\
\text { Pu: IRMM 49d }\end{array}$ & $\begin{array}{c}\text { U: IRMM } 054 \\
\text { Nd: }{ }^{150} \mathrm{Nd} \text { material }\end{array}$ & IRMM 46c \\
\hline$(\% B)_{T}$ & $5.4102 \%$ & $0.8042 \%$ & $5.4102 \%$ & $0.2099 \%$ \\
\hline$(\% A)_{T}$ & $93.176 \%$ & $98.0430 \%$ & $93.176 \%$ & $99.763 \%$ \\
\hline$C(E)_{C R M \text { or } T}$ & $0.0404 \times 10^{-6}$ & $0.10303 \times 10^{-6}$ & $0.0404 \times 10^{-6}$ & $4.4742 \times 10^{-6}$ \\
\hline$u_{r}\left(\left(\frac{E}{{ }^{A} E}\right)\right.$ & $0.0300 \%$ & $0.122 \%$ & $0.0300 \%$ & $0.000927 \%$ \\
\hline$(\% Y)_{T}$ & $0.50446 \%$ & $0.50446 \%$ & $0.93850 \%$ & $0.50446 \%$ \\
\hline$(\% X)_{T}$ & $94.622 \%$ & $94.622 \%$ & $94.745 \%$ & $94.622 \%$ \\
\hline$C(Z)_{C R M \text { or } T}$ & $0.0183 \times 10^{-6}$ & $0.0183 \times 10^{-6}$ & $0.0499 \times 10^{-6}$ & $0.37519 \times 10^{-6}$ \\
\hline$u_{r}\left(\left(\frac{Z}{{ }^{X} Z}\right)\right.$ & $0.0646 \%$ & $0.0646 \%$ & $0.170 \%$ & $0.00204 \%$ \\
\hline$u_{r}\left(\left(\frac{\mathbf{L}}{A_{E}}\right)\right.$ & $0.136 \%$ & $0.0924 \%$ & $0.282 \%$ & $0.0227 \%$ \\
\hline$(\% B)_{S}$ & $99.310 \%$ & $99.310 \%$ & $99.310 \%$ & $99.310 \%$ \\
\hline$(\% A)_{S}$ & $0.45640 \%$ & 0 & $0.45640 \%$ & 0 \\
\hline$C(E)_{S}$ & $0.209 \times 10^{-6}$ & $0.209 \times 10^{-6}$ & $0.209 \times 10^{-6}$ & $0.209 \times 10^{-6}$ \\
\hline$u_{r}\left(\left(\frac{{ }^{B}}{{ }^{B} E}\right)_{S}\right)$ & $0.138 \%$ & 0 & $0.138 \%$ & 0 \\
\hline$(\% Y)_{S}$ & $74.010 \%$ & $74.010 \%$ & $10.447 \%$ & $74.010 \%$ \\
\hline$(\% X)_{S}$ & $15.745 \%$ & $15.745 \%$ & $6.308 \%$ & $15.745 \%$ \\
\hline$C(Z)_{S}$ & $0.0141 \times 10^{-6}$ & $0.0141 \times 10^{-6}$ & $0.000569 \times 10^{-6}$ & $0.0141 \times 10^{-6}$ \\
\hline$u_{r}\left(\left(\frac{\mathbf{L}}{Y^{\prime} Z}\right)\right.$ & $0.0994 \%$ & $0.0994 \%$ & $0.261 \%$ & $0.0994 \%$ \\
\hline
\end{tabular}




\begin{tabular}{|c|c|c|c|c|}
\hline & $0.07 \%$ & $0.07 \%$ & $0.07 \%$ & $0.07 \%$ \\
\hline$u_{r}$ & $0.07 \%$ & $0.07 \%$ & $0.07 \%$ & $0.07 \%$ \\
\hline
\end{tabular}
324 

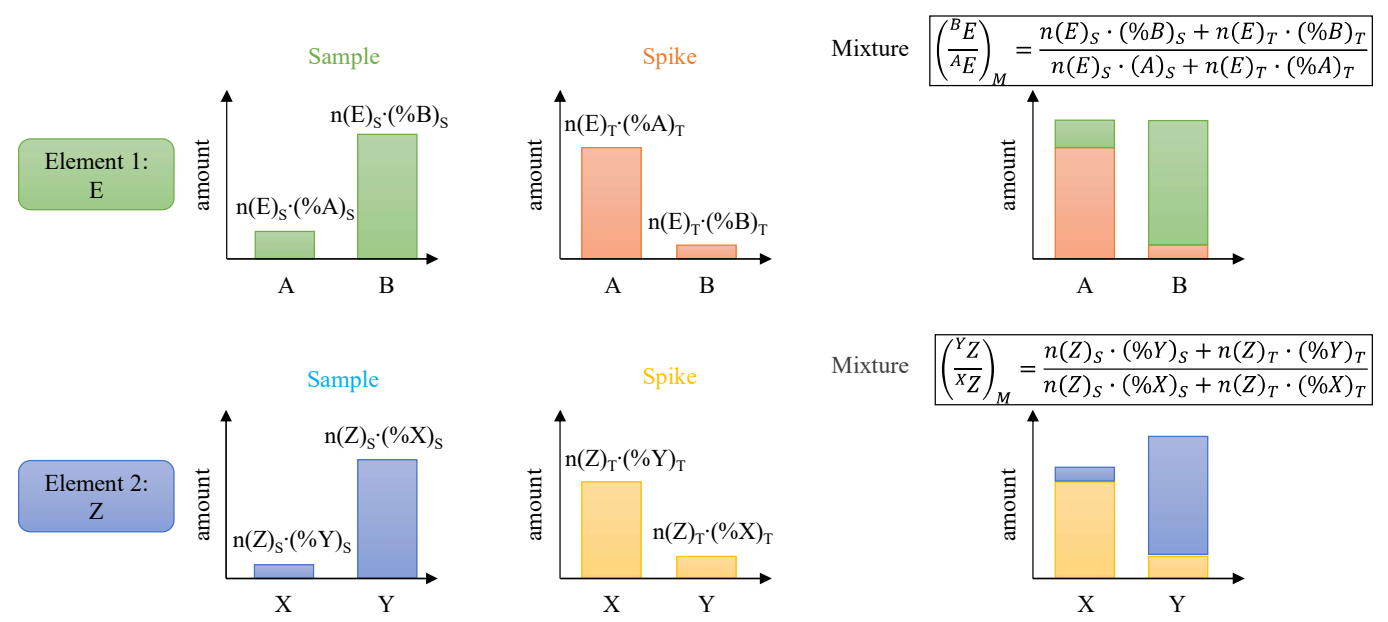

Fig. 1: Schematics of the DID methodology

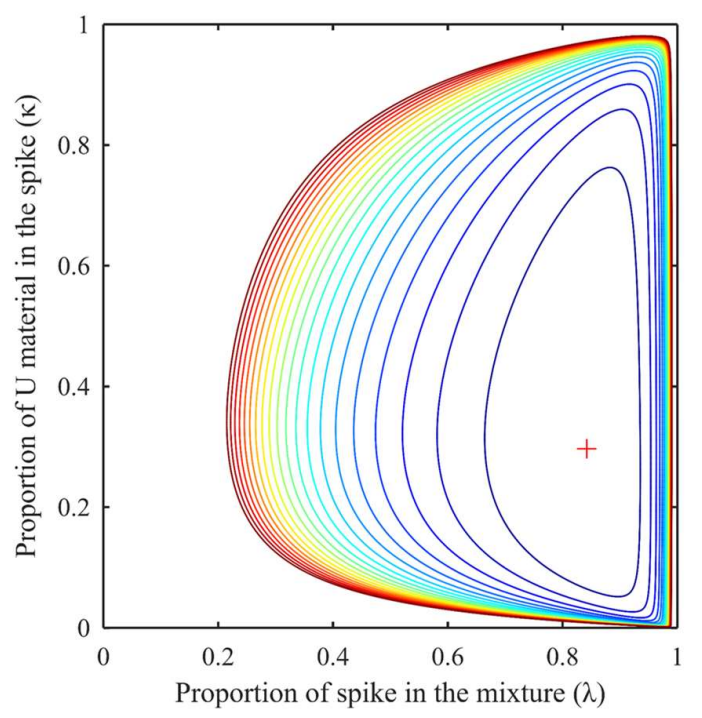

331 Fig. 2: Contour plot of error for the relative uncertainty of the sample ${ }^{238} \mathrm{Pu} /{ }^{238} \mathrm{U}$ ratio using U (IRMM-054) and Pu (IRMM-049d) CRM (example 1 in Table 1). The optimum is marked by the cross. The plot is cut off so that only contours within $20 \%$ 


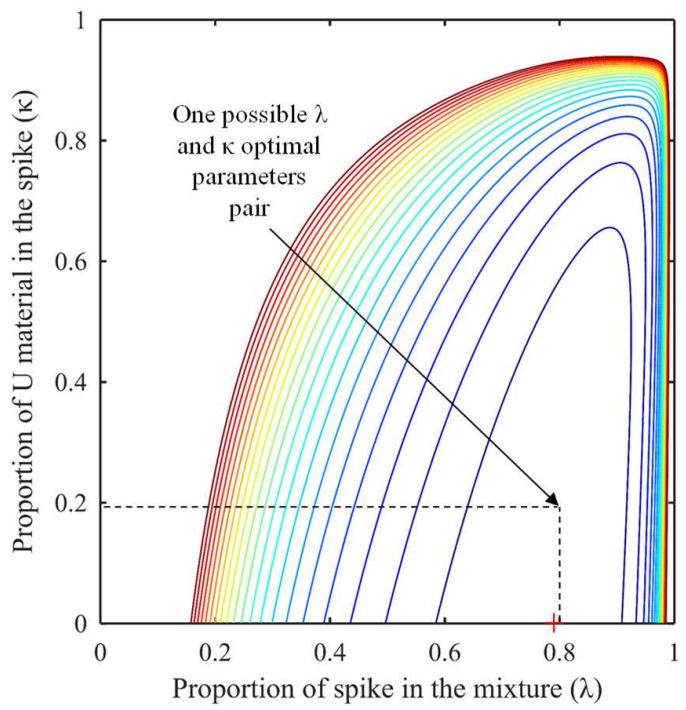

339 Fig. 3: Contour plot of error for the relative uncertainty of the sample ${ }^{238} \mathrm{Pu} /{ }^{238} \mathrm{U}$ ratio using U (IRMM-051) and Pu (IRMM-49d) CRM (example 2 in Table 1). The optimum is marked by the cross. The plot is cut off so that only contours within $20 \%$ 

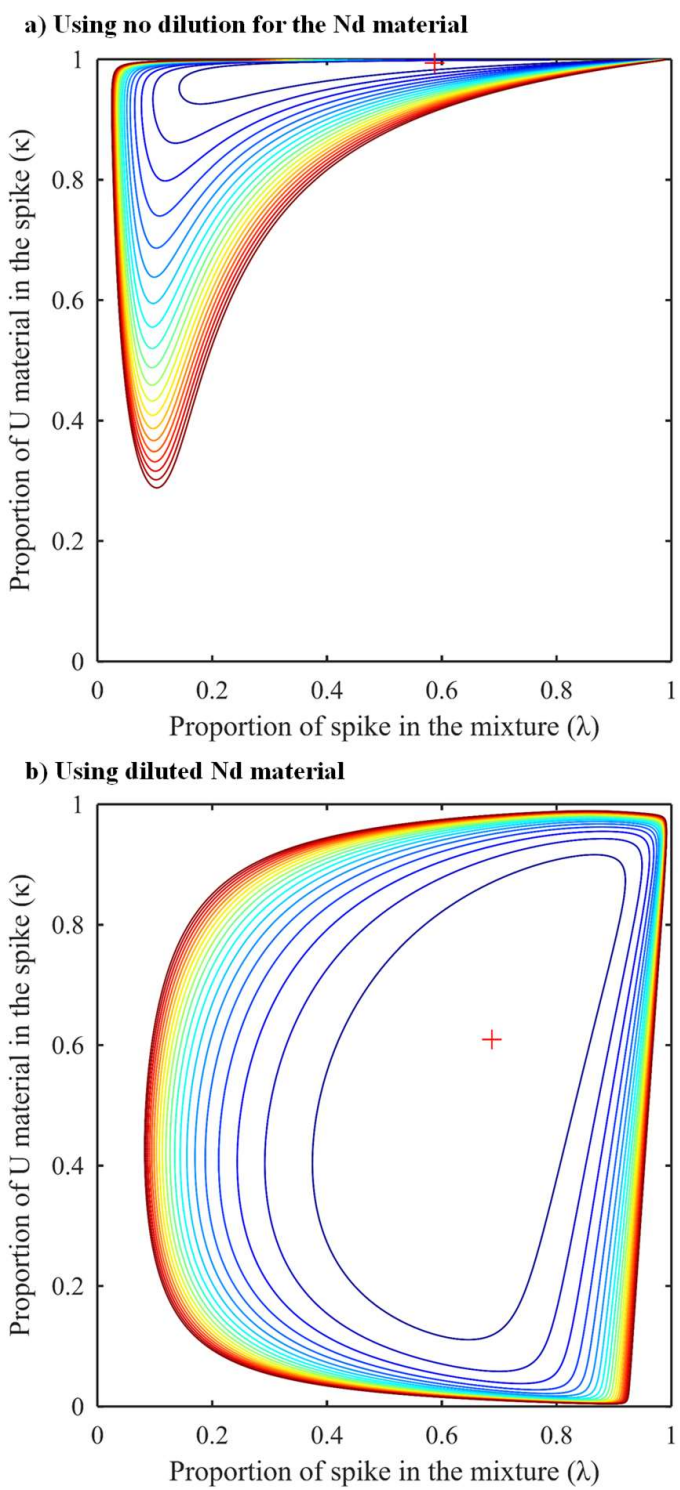

345 Fig. 4: Contour plot of error for the relative uncertainty of the sample ${ }^{148} \mathrm{Nd} /{ }^{238} \mathrm{U}$ ratio using U CRM (IRMM 054) and no diluted (a) and diluted (b) Nd material (example 3 in Table 1). The plot is cut off so that only contours within $20 \%$ of the minimal error are shown. The contours are spaced out with intervals of $1 \%$ of the minimal error 
a) Using IRMM-046c CRM without dilution

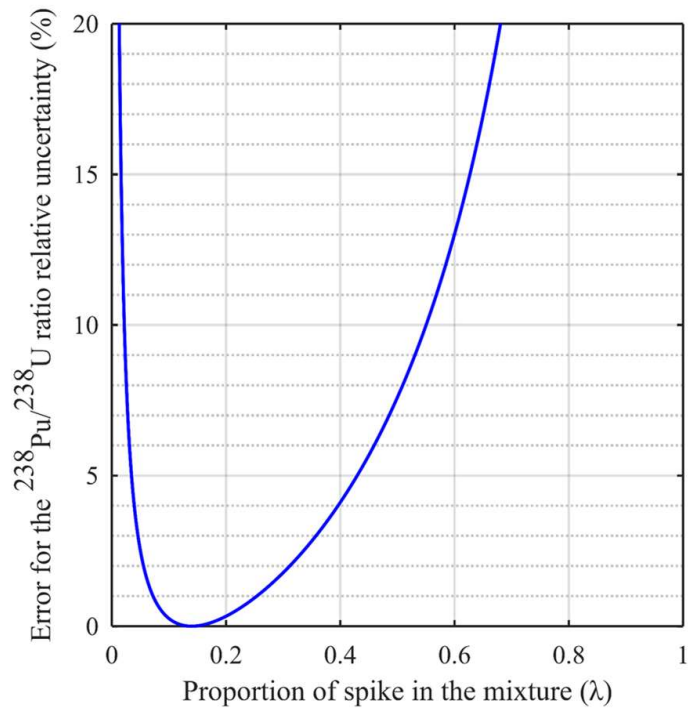

b) Using IRMM-046c CRM diluted 10 times

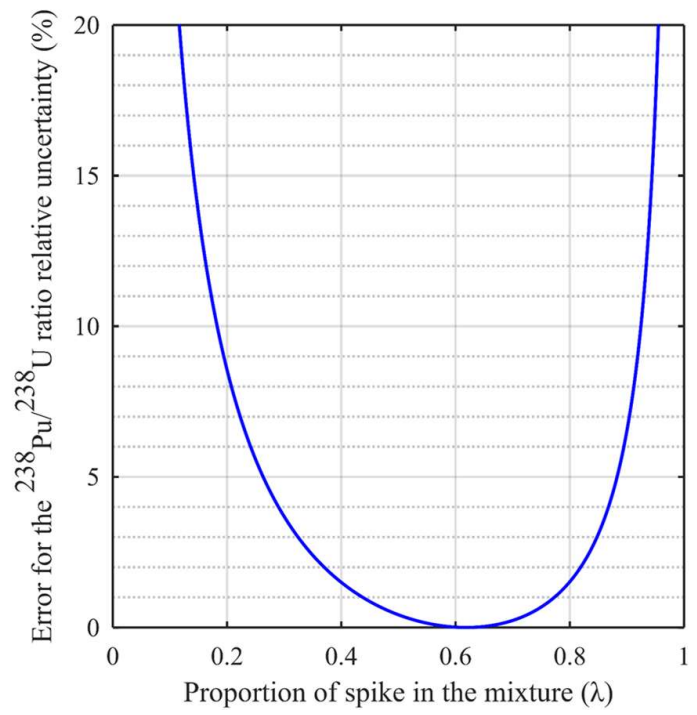

350 Fig. 5: Error for the ${ }^{238} \mathrm{Pu} /{ }^{238} \mathrm{U}$ ratio relative uncertainty $(\%, \mathrm{k}=1)$ as a function of $\lambda$ 351 parameter using the IRMM-046c CRM without dilution (a) and diluted 10-fold (b) 352 


\section{References}

357 1. Bachhav M, Gan J, Keiser D, Giglio J, Jädernäs D, Leenaers A, Van den

358 Berghe S (2020) A novel approach to determine the local burnup in irradiated

359

360

361

362

363

364

365

366 fuels using Atom Probe Tomography (APT). J Nucl Mater 528:. https://doi.org/10.1016/j.jnucmat.2019.151853

2. Devida C, Betti M, Peerani P, Toscano EH, Goll W (2004) Quantitative Burnup Determination: A Comparision of Different Experimental Methods. In: "HOTLAB” Plenary Meeting. Halden, Norway, pp 106-113

3. Wolf SF, Bowers DL, Cunnane JC (2005) Analysis of high burnup spent nuclear fuel by ICP-MS. J Radioanal Nucl Chem 263:581-586. https://doi.org/10.1007/s10967-005-0627-7

4. Quemet A, Buravand E, Peres J-G, Dalier V (2021) Irradiated UAmO2 transmutation discs analyses: from dissolution to accurate isotopic analyses. $\mathbf{J}$ Radioanal Nucl Chem To be subm:To be submitted

5. Bourgeois M, Isnard H, Gourgiotis A, Stadelmann G, Gautier C, Mialle S, Nonell A, Chartier F (2011) Sm isotope composition and $\mathrm{Sm} / \mathrm{Eu}$ ratio determination in an irradiated 153 Eu sample by ion exchange chromatographyquadrupole inductively coupled plasma mass spectrometry combined with double spike isotope dilution technique. J Anal At Spectrom 26:1660-1666. https://doi.org/10.1039/c1ja10070j

6. Chartier F, Aubert M, Pilier M (1999) Determination of Am and Cm in spent nuclear fuels by isotope dilution inductively coupled plasma mass spectrometry and isotope dilution thermal ionization mass spectrometry after separation by high-performance liquid chromatography. Fresenius J Anal Chem 364:320-327

7. Beattie P (1993) Uranium-thorium disequilibria and partitioning on melting of garnet peridotite. Nature 363:63-65. https://doi.org/10.1038/363063a0

8. Condomines M, Allegre CJ (1976) Evidence for contamination of recent Hawaiian lavas from 230Th-238U data. Earth Planet Sci Lett 33:122-125. https://doi.org/10.1016/0012-821X(76)90165-5 
385

386

387

388

389

390

391

392

393

394

395

396

397

398

399

400

401

402

403

404

405

406

407

408

409

410

411

412

413

9. Condomines M, Hemond C, Allègre CJ (1988) UThRa radioactive disequilibria and magmatic processes. Earth Planet Sci Lett 90:243-262.

https://doi.org/10.1016/0012-821X(88)90129-X

10. Jia GD, Chabaux F, Van der Woerd J, Pelt E, di Chiara Roupert R, Ackerer J, Zhao ZQ, Yang Y, Xu S, Liu CQ (2021) Determination of regolith production rates from $238 \mathrm{U}-234 \mathrm{U}-230 \mathrm{Th}$ disequilibrium in deep weathering profiles (Longnan, SE China). Chem Geol 574:. https://doi.org/10.1016/j.chemgeo.2021.120241

11. Shao QF, Li CH, Huang MJ, Liao ZB, Arps J, Huang CY, Chou YC, Kong XG (2019) Interactive programs of MC-ICPMS data processing for $230 \mathrm{Th} / \mathrm{U}$ geochronology. Quat Geochronol 51:43-52. https://doi.org/10.1016/j.quageo.2019.01.004

12. Ghaleb B, Falguères C (2017) Apport des méthodes basées sur le déséquilibre radioactif (238U-234U-230Th-226Ra-210Pb) aux études des variations et changements climatiques. Anthropol 121:73-81. https://doi.org/10.1016/j.anthro.2017.03.008

13. Mayer K, Wallenius M, Lützenkirchen K, Horta J, Nicholl A, Rasmussen G, Van Belle P, Varga Z, Buda R, Erdmann N, Kratz JV, Trautmann N, Fifield LK, Tims SG, Fröhlich MB, Steier P (2015) Uranium from German Nuclear Power Projects of the 1940s - A Nuclear Forensic Investigation. Angew Chemie - Int Ed 54:13452-13456. https://doi.org/10.1002/anie.201504874

14. Quemet A, Maillard C, Ruas A (2015) Determination of zirconium isotope composition and concentration for nuclear sample analysis using Thermal Ionization Mass Spectrometry. Int J Mass Spectrom 392:34-40. https://doi.org/10.1016/j.ijms.2015.08.023

15. Quemet A, Ruas A, Esbelin E, Dalier V, Rivier C (2019) Development and comparison of two high accuracy methods for uranium concentration in nuclear fuel: ID-TIMS and K-edge densitometry. J Radioanal Nucl Chem 321:9971004. https://doi.org/10.1007/s10967-019-06670-y 
414 16. Quemet A, Ruas A, Dalier V, Rivier C (2018) Americium isotope analysis by 415 Thermal Ionization Mass Spectrometry using the Total Evaporation Method.

416 Int J Mass Spectrom 431:8-14. https://doi.org/10.1016/j.ijms.2018.05.017

417 17. Vogl J (2007) Characterisation of reference materials by isotope dilution mass 418 spectrometry. J Anal At Spectrom 22:475-492.

419 https://doi.org/10.1039/b614612k

420 18. Rodríguez-González P, Ignacio García Alonso J (2019) Mass spectrometry |

421 Isotope dilution mass spectrometry. Encycl Anal Sci 6:411-420.

422 https://doi.org/10.1016/B978-0-12-409547-2.14387-2

423 19. Rudge JF, Reynolds BC, Bourdon B (2009) The double spike toolbox. Chem

424 Geol 265:420-431. https://doi.org/10.1016/j.chemgeo.2009.05.010

425 20. Désenfant M, Priel M (2017) Reference and additional methods for 426 measurement uncertainty evaluation. Measurement 95:339-344

427 21. Eaton JW (2012) GNU Octave and reproducible research. J Process Control $428 \quad 22: 1433-1438$. https://doi.org/10.1016/j.jprocont.2012.04.006

429 22. Quemet A, Angenieux M, Ruas A (2021) Nd, Am and Cm isotopic 430 measurement after simultaneous separation in transmutation irradiated samples. $431 \quad$ J Anal At Spectrom 36:1758. https://doi.org/10.1039/D1JA00165E

432 23. Esbelin E (2014) Graphite monochromator for actinide L-line energy 433 dispersive X-ray fluorescence analysis in liquid sample. X-Ray Spectrom $434 \quad 43: 198-208$. https://doi.org/10.1002/xrs.2540

435 24. International Atomic Energy Agency (2010) International Target Values 2010 436 for Measurement Uncertainties in Safeguarding Nuclear Materials - STR368. $437 \quad$ Vienna, Austria 